\title{
Patterns of Initiation of Oral Anticoagulants in Patients with Atrial Fibrillation-Quality and Cost Implications
}

\section{Citation}

Desai, Nihar R., Alexis A. Krumme, Sebastian Schneeweiss, William H. Shrank, Gregory Brill, Edmund J. Pezalla, Claire M. Spettell, et al. 2014. "Patterns of Initiation of Oral Anticoagulants in Patients with Atrial Fibrillation- Quality and Cost Implications." The American Journal of Medicine 127 (11) (November): 1075-1082.e1. doi:10.1016/j.amjmed.2014.05.013.

\section{Published Version}

doi:10.1016/j.amjmed.2014.05.013

\section{Permanent link}

http://nrs.harvard.edu/urn-3:HUL.InstRepos:36880594

\section{Terms of Use}

This article was downloaded from Harvard University's DASH repository, and is made available under the terms and conditions applicable to Open Access Policy Articles, as set forth at http:// nrs.harvard.edu/urn-3:HUL.InstRepos:dash.current.terms-of-use\#OAP

\section{Share Your Story}

The Harvard community has made this article openly available.

Please share how this access benefits you. Submit a story.

\section{Accessibility}




\section{Patterns of Initiation of Oral Anticoagulants in Patients with Atrial Fibrillation - Quality and Cost Implications}

Nihar R. Desai, MD, MPH; Alexis A. Krumme, MS; Sebastian Schneeweiss, MD, ScD; William H. Shrank, MD, MSHS; Gregory Brill, MS; Edmund J. Pezalla, MD, MPH; Claire M. Spettell, PhD; Troyen A. Brennan, MD, JD, MPH, Olga S. Matlin, PhD; Jerry Avorn, MD; Niteesh K. Choudhry, MD, PhD

Author affiliations: Division of Pharmacoepidemiology and Pharmacoeconomics (NRD, AAK, SS, WHS, GB, JA, NKC), Department of Medicine, Brigham and Women's Hospital and Harvard Medical School, Boston, MA; Section of Cardiovascular Medicine, Department of Medicine, Yale School of Medicine; Center for Outcomes Research and Evaluation, Yale-New Haven Health Services Corporation, New Haven, CT (NRD); CVS Caremark (WHS, TB, OM); Aetna (EJP, CMS)

Running Title: Oral Anticoagulant Use in Atrial Fibrillation

Address for correspondence: Niteesh K. Choudhry, MD, PhD, Brigham and Women's Hospital, Harvard Medical School, 1620 Tremont Street, Suite 3030, Boston, MA 02120. Phone: 617-278-0930. Fax: 617-232-8602. Email: nchoudhry@partners.org.

FUNDING: This work was funded by an unrestricted research grant from CVS Caremark to Brigham and Women's Hospital

\section{ACKNOWLEDGEMENTS:}

TOTAL WORD COUNT: 271 (Abstract); 2,841 (Text)

6 text pages; 25 references; 2 tables; 4 figures; 1 appendix 


\begin{abstract}
BACKGROUND: Dabigatran, rivaroxaban, and apixaban have been approved for use in patients with atrial fibrillation based upon randomized trials demonstrating their comparable or superior efficacy and safety relative to warfarin. Little is known about their adoption into clinical practice, whether utilization is consistent with the controlled-trials on which their approval was based, and how their use has affected health spending for patients and insurers.

STUDY DESIGN: We used medical and prescription claims data from a large insurer to identify patients with non-valvular atrial fibrillation who were prescribed an oral anticoagulant in 2010-2013. We plotted trends in medication initiation over time, assessed corresponding insurer and patient out-of-pocket spending, and evaluated the cumulative number and cost of anticoagulants. We identified predictors of novel anticoagulant initiation using multivariable logistic models. Finally, we estimated the difference in total drug expenditures over 6 months for patients initiating warfarin vs. a novel anticoagulant. RESULTS: 6,893 patients with atrial fibrillation initiated an oral anticoagulant during the study period. By the end of the study period, novel anticoagulants accounted for $62 \%$ of new prescriptions and $98 \%$ of anticoagulant-related drug costs. Female sex, lower household income and higher $\mathrm{CHADS}_{2}, \mathrm{CHA}_{2} \mathrm{DS}_{2}$-VASC, and HAS-BLED scores were significantly associated with lower odds of receiving a novel anticoagulant $(\mathrm{p}<0.001$ for each). Average combined patient and insurer anticoagulant spending in the first 6 months after initiation was more than $\$ 900$ greater for patients initiating a novel anticoagulant. CONCLUSIONS: This study demonstrates rapid adoption of novel anticoagulants into clinical practice, particularly among patients with lower $\mathrm{CHADS}_{2}$ and HAS-BLED scores, and high health care cost consequences. These findings provide important directions for future comparative and cost-effectiveness research.
\end{abstract}

KEYWORDS: novel anticoagulant; warfarin; vitamin K antagonist; Factor Xa inhibitor; patterns of use; 


\section{INTRODUCTION}

Warfarin and other vitamin $\mathrm{K}$ antagonists significantly reduce the risk of stroke and death in patients with non-valvular atrial fibrillation and have long been the cornerstone of therapy for this condition. ${ }^{1}$ Though these drugs are inexpensive, they require monitoring, have a narrow therapeutic window, and patients frequently discontinue use. ${ }^{2}$ Novel oral anticoagulants that require no monitoring have been approved for use based upon randomized trials demonstrating their comparable or superior efficacy and safety relative to warfarin. ${ }^{3-5}$ Based on these studies, the US Food and Drug Administration approved the direct thrombin inhibitor dabigatran, in October 2010, followed by the Factor Xa inhibitors rivaroxaban and apixaban in November 2011 and December 2012, respectively.

A national audit of ambulatory practices evaluating trends in oral anticoagulant use from 2007 to 2011 found rapid adoption of dabigatran in clinical practice. ${ }^{6}$ Similarly, a recent registry-based analysis of the use of dabigatran in patients with atrial fibrillation found significant uptake of dabigatran use in $2011 .^{7}$ However, little is known about how the availability of rivaroxaban and apixaban have affected utilization patterns, whether the adoption of the novel anticoagulants in typical practice is consistent with the controlled trials on which their approval was based, or how their use has affected spending for patients and insurers.

\section{METHODS}

\section{Study population and data source}

We used nationwide medical and prescription claims data from commercial patients covered by Aetna, a large health care benefits company, to create a cohort of patients with newly diagnosed non-valvular atrial fibrillation who were prescribed an oral anticoagulant between October 1, 2010 and June 30, 2013.

These data contained complete paid claims data for all procedures, physician encounters, hospitalizations, and filled prescriptions (including dose dispensed and amounts paid by the insurer and the patient). These data were linked to eligibility data that included patient age, gender, and zip code of residence. Aggregate data on socioeconomic status, race, and educational attainment were obtained by linking zip code of residence with data from the 2000 United States Census, which specified the median income as well as the distribution of race and educational achievement of the geographic population for each zip code. The Institutional Review Board of Brigham and Women's Hospital approved the study.

\section{Study cohort}

Patients were included in the study if they filled a prescription for warfarin, dabigatran, rivaroxaban, or apixaban during the study period. All patients were required to have maintained continuous insurance eligibility for 6 months prior to their index date, during which time they must have had a diagnosis of atrial fibrillation (International Classification of Diseases, Ninth Revision [ICD-9]: 427.31) and no filled prescriptions for any anticoagulant agent (i.e. they were new initiators). Patients with concomitant valvular heart disease (ICD-9: 394.x-397.x, 398.9, 42.4x, V42.2, V43.3, 35.1x, 35.2x) were excluded. 
Any subsequent re-initiation of therapy by a patient that met cohort entry criteria was excluded (i.e. a patient could only appear in the cohort once). The date of the patient's first eligible prescription was defined as his or her index date.

We assessed differences in proportions and means with 95\% confidence intervals for demographic, clinical and healthcare utilization characteristics of initiators of warfarin, dabigatran, and rivaroxaban; apixaban was excluded from these statistical comparisons due to small sample size. Clinical and healthcare utilization characteristics were based on medical and pharmacy claims in the 6 months prior to initiation. The Congestive heart failure, Hypertension, Age $\geq 75$ years, Diabetes mellitus, Stroke $\left(\mathrm{CHADS}_{2}\right)$ score $^{8}$, the Congestive heart failure, Hypertension, Age $\geq 75$ years, Diabetes mellitus, Stroke, Vascular disease, Age 65-74 years, Sex category ( $\mathrm{CHA}_{2} \mathrm{DS}_{2}$-VASc) score ${ }^{9}$, and the Hypertension, Abnormal renal/liver function, Stroke, Bleeding history or predisposition, Labile international normalized ratio, Elderly (Age > 65 years), Drugs/alcohol concomitantly (HAS-BLED) score ${ }^{10}$ was calculated for each subject (Note: One element of this score, labile INR values, was not available in our claims dataset and therefore was not used in the HASBLED score calculation). Individuals with unknown gender were excluded.

\section{Patterns and predictors of initiation}

We categorized patients based on calendar month of their drug initiation and the oral anticoagulant which they started, and plotted trends over time. We then assessed insurer drug spending (i.e. plan-paid amount) and patient out-of-pocket drug spending (i.e. copayments, coinsurance, deductible) based on the index prescription, and plotted the share of costs associated with each anticoagulant. Finally, we plotted the cumulative total monthly number of prescriptions of each anticoagulant after the index prescription, regardless of any switching that might have occurred, and computed the monthly costs associated with these prescriptions. Patients who lost eligibility were censored at loss of eligibility. We repeated our plots of trends in anticoagulant initiation stratified on $\mathrm{CHADS}_{2}$ score $^{8}$, a stroke prediction score.

We constructed three multivariable logistic models to identify predictors of initiation on a novel oral anticoagulant compared with warfarin. Potential predictors in all models included age, gender, race, income, geographic region, and calendar time. Comorbidity was adjusted for in several ways: 1) investigator-selected diagnoses; 2) CHADS $_{2}$ score; and 3) HAS-BLED score.

\section{Economic analysis}

To evaluate patient and insurer costs associated with anticoagulant use over the 6 month period after treatment initiation, we restricted our cohort to those individuals with 180 days or more of continuous eligibility after their first prescription. For each patient, we calculated total patient out-of-pocket and insurer spending for all anticoagulant medication during the 180 days after treatment initiation, including anticoagulant medications the patients may have switched to during this period. We then subdivided these estimates into patient out-of-pocket and insurer spending for the index medication and for other anticoagulants. From this, we estimated the difference in total expenditures over 6 months for patients initiating warfarin compared to a novel anticoagulant. 


\section{RESULTS}

The study cohort consisted of 6,893 patients with non-valvular atrial fibrillation newly initiated on an oral anticoagulant between October 1, 2010 and June 30, 2013 (Appendix A). Patients had a mean age of 61.3 years, were predominantly male $(72.8 \%)$, and had mean $\mathrm{CHADS}_{2}$ and HAS-BLED scores of 1.7 and 2.0, respectively (Table 1 ). Approximately one third of patients had a history of coronary artery disease, while one quarter had diabetes. Heart failure, renal dysfunction, history of stroke or transient ischemic attack was present in 17\%, 12\%, and 9\% of patients, respectively, while $4 \%$ had a history of gastrointestinal bleeding. On average, patients had filled more than 8 medications in the 6 months prior to treatment initiation; $13 \%$ had received a nonsteroidal anti-inflammatory medication and $8 \%$ had received clopidogrel in the 6 months prior to initiation.

\section{Patterns of Medication Initiation over Time}

Over the 36-month study period, there were a total of 45,472 prescriptions filled for anticoagulants, among which 26,253 (57.7\%) were for warfarin, 14,922 (32.8\%) for dabigatran, 4,241 (9.3\%) for rivaroxaban and $56(0.1 \%)$ for apixaban.

Dabigatran rapidly gained market share after entering the market in November 2010 (Figure 1A). By October 2011, patients were as likely to start on this drug as they were to initiate warfarin. After its introduction, rivaroxaban use increased rapidly, overtaking both warfarin and dabigatran in June 2013. Apixaban, only FDA-approved as of December 2012 , saw only modest uptake, accounting for only $2 \%$ of new anticoagulant prescriptions as of June 2013.

\section{Predictors of initiating treatment with a novel oral anticoagulant}

As compared with patients initiating warfarin, those starting a novel oral anticoagulant had significantly fewer concomitant medications, office visits, hospital days, and hospitalizations within 30 days of initiation but higher number of visits to a cardiologist $(\mathrm{p}<0.001)$ (Table 1). Novel anticoagulant initiators tended to be younger and healthier, and with significantly lower $\mathrm{CHADS}_{2}, \mathrm{CHA}_{2} \mathrm{DS}_{2}$-VASC, and HAS-BLED scores. As seen in Figure 2, 46\% of patients with $\mathrm{CHADS}_{2}$ scores of 0 or 1 initiated a novel anticoagulant, compared to just 39\% and 26\% for $\mathrm{CHADS}_{2}$ scores of 2 and 3, respectively $(\mathrm{p}<0.0001$ for test of trend).

In multivariable models, increasing $\mathrm{CHADS}_{2}$ and HAS-BLED scores were significantly associated with lower odds of novel anticoagulant initiation (Table 2). For every one point increase in $\mathrm{CHADS}_{2}$, patients were $20 \%$ less likely to receive a novel anticoagulant (odds ratio $0.80 ; 95 \%$ confidence interval 0.76 to 0.84 ). Similarly, for every one point increase in HAS-BLED, patients were $18 \%$ less likely to receive a novel anticoagulant (odds ratio 0.82 ; $95 \%$ confidence interval 0.78 to 0.87 ). In addition, women were $24 \%$ less likely to be initiated on a novel oral anticoagulant as compared with men (odds ratio 0.76; 95\% confidence 0.67 to 0.86 ). There was a significant, step-wise increase in the likelihood of 
receiving a novel agent with progressively increasing neighborhood household income, compared with median household income of $\$ 50,000$ or less.

\section{Economic impact of initial medication choice}

Trends in monthly spending are shown in Figure 1B. Since the introduction of dabigatran in late 2010, novel anticoagulant spending has accounted for $98 \%$ of total spending. This corresponds to insurer spending of $\$ 5.82$ million, of which warfarin accounted for $\$ 0.43$ million (Figure $3 \mathrm{~A}$ ), and patient out-of-pocket spending of $\$ 1.3$ million of which warfarin accounted for $\$ 3,844$ (Figure 3B).

Considering only the first 6 months post-initiation, total out-of-pocket and insurer costs for patients initiating a novel anticoagulant were considerably higher than those for patients initiating warfarin (Figure 4). On average, patients initiating warfarin paid \$54 for 6 months of medication, while those initiating dabigatran or rivaroxaban paid $\$ 205$ and $\$ 221$, respectively. Insurer spending for patients initiated on warfarin during this period was $\$ 68$ for warfarin compared to $\$ 852$ and $\$ 865$ for dabigatran and rivaroxaban, respectively. The average combined patient and insurer spending for anticoagulants over 6 months for patients initiating warfarin was $\$ 122$, dabigatran $\$ 1053$, and rivaroxaban $\$ 1084$. This represents a difference over 6 months of more than $\$ 900$ per patient.

\section{DISCUSSION}

This study of a contemporary cohort of patients with atrial fibrillation starting oral anticoagulant therapy demonstrates rapid adoption of novel anticoagulants into clinical practice, utilization associated with lower CHADS $_{2}$ and HAS-BLED scores, and significant health care cost implications. This study is the first to our knowledge to evaluate realworld use of all novel anticoagulants currently on the market. ${ }^{6}$

We observed a significant decline in the proportion of patients with atrial fibrillation starting warfarin concurrent with the availability of novel anticoagulants beginning in October 2010. By June 2013, more than $60 \%$ of patients newly initiating an oral anticoagulant were being prescribed dabigatran, rivaroxaban, or apixaban. Prior to the introduction of rivaroxaban in November, 2011, dabigatran accounted for $44 \%$ of anticoagulant initiation, but this dropped to approximately $15 \%$ of starts in the subsequent 12 months, a reversal that may have been related to reports beginning in late 2011 of increased risk of myocardial infarction and serious and fatal bleeding events in dabigatran users $11,12,13$. The once-daily dosing of rivaroxaban as compared with twice daily for dabigatran may also be a factor in the substitution away from dabigatran.

With only $2 \%$ of market share 6 months after approval, it remains to be seen whether the adoption of apixaban will follow the same trajectory as dabigatran and rivaroxaban. The impending FDA approval of new factor Xa inhibitors such as edoxaban ${ }^{14,15}$ and betrixaban ${ }^{16}$ may also influence an increasingly crowded market for therapeutic alternatives to warfarin. It remains unclear whether the market for novel anticoagulants has been fully saturated and whether uptake of one drug will generally occur at the expense of other novel agents, or whether aggressive promotion of this class 
will result in an overall increase in the use of anticoagulants in patients with atrial fibrillation and market expansion for all therapies.

We found similar use of warfarin and novel anticoagulants among patients with $\mathrm{CHADS}_{2}$ score of 0 or 1 , with progressively higher use of warfarin among patients with $\mathrm{CHADS}_{2}$ of 2 and then predominant use of warfarin among patients with $\mathrm{CHADS}_{2}$ of 3 or greater. In a multivariate model, higher $\mathrm{CHADS}_{2}$ and HAS-BLED scores were associated with a significantly lower odds of initiating therapy with a novel agent, results which are corroborated by a recent registry-based analysis of the adoption of dabigatran. ${ }^{7}$ These patterns of adoption demonstrate some divergence from the clinical trials on whose basis the novel anticoagulants were approved. Notably, the mean CHADS $_{2}$ scores for the Randomized Evaluation of Long-Term Anticoagulation therapy ${ }^{3}$ (RE-LY), Rivaroxaban Once Daily Oral Direct Factor Xa Inhibition Compared with Vitamin K Antagonism for Prevention of Stroke and Embolism Trial in Atrial Fibrillation (ROCKET-AF) ${ }^{4}$, and Apixaban for Reduction in Stroke and Other Thromboembolic Events in Atrial Fibrillation (ARISTOTLE) ${ }^{5}$ trials were 2.1, 3.5, and 2.1 respectively and eligibility criteria for the ROCKET-AF trial was based on a CHADS 2 score of at least 2 (in fact, enrollment for patients with $\mathrm{CHADS}_{2}$ of 2 was limited to 10\%). ${ }^{4}$ The greatest absolute benefit from novel anticoagulants has been shown to be among patients at highest baseline risk for stroke or systemic embolization, which is at odds with our observation of selection of seemingly lower risk patients for these drugs. Such a finding may reflect provider conservatism for new drug adoption, particularly given longitudinal experience with warfarin. Nonetheless, given this finding as well as the potential disparities in the use of novel anticoagulants based on geography, sex, and income, it will be important to conduct ongoing surveillance of the penetration of novel anticoagulants and whether this initial phase with dominant use among lower risk patients is followed by use in more high risk patients or whether a significant selection bias persists in the patients for whom they are prescribed.

Our observation that users of the newer anticoagulants were generally healthier and had a lower stroke risk than warfarin users has important implications for surveillance data concerning their propensity to cause bleeding, as well as likely future observational comparative effectiveness studies. An early population-based assessment performed by the FDA documented substantially lower rates of intracerebral and gastrointestinal hemorrhage in atrial fibrillation patients taking dabigatran versus warfarin, ${ }^{17}$ but did not adjust for any differences in risk among the two patient groups, nor for age or gender. 18 The differences we have documented in the levels of comorbidity among users of these agents will need to be taken into account in any future observational studies of the drugs' outcomes.

The observed patterns of anticoagulant initiation among patients with atrial fibrillation additionally have important economic implications for patients, payers, and the health care system. Average patient out-of-pocket and insurance spending was more than 5 and 15-fold higher, respectively, for novel anticoagulants as compared to warfarin. Novel anticoagulants have only recently attained greater than $50 \%$ of market share, yet have accounted for more than $90 \%$ of insurer spending on anticoagulants since the introduction of dabigatran in 2010. A six-month difference in total costs of $\$ 900$ in our cohort translates into billions of dollars at a national level. 
Whereas registration trials for these agents have demonstrated clinical superiority and at least equal safety to warfarin, ${ }^{3-5}$ the cost effectiveness of these drugs in routine care has not been conclusively evaluated. Early analyses were limited by uncertainty or error concerning the pricing of both warfarin and its newer competitors. ${ }^{19}$ Canestaro et al. found that apixaban appears to be cost-effective at a willingness-to-pay threshold of $\$ 100,000$, but noted substantial uncertainty in this estimate in probabilistic sensitivity analyses. ${ }^{20}$ Limone et al.'s meta-analysis of cost-effectiveness models for novel anticoagulants showed high model heterogeneity, including incremental-cost-effectiveness ratios for dabigatran as compared to warfarin ranging from $\$ 3,547$ to $\$ 86,000.21$ An analysis based on the RE-LY clinical trial concluded that, contrary to the patterns of anticoagulant use we observed, warfarin is the optimal strategy among patients with lower CHADS $_{2}$ scores. $^{22}$

There are several limitations to our analysis. First, our study relied on administrative claims data for study inclusion as well as clinical characteristics. Though misclassification of patients with non-valvular atrial fibrillation could have occurred, we used well-standardized methods and approaches. ${ }^{23,24}$ While we lacked detailed clinical information, we did integrate medical claims data with prescription claims data to more fully examine patterns of novel anticoagulant utilization. Second, several demographic factors, including race, income level, and educational attainment were derived from census data, assessed at the zip-code level. Third, our analysis of anticoagulant use among privately insured patients may not be representative of treatment patterns among patients with Medicare, Medicaid, or uninsured patients. However, to the extent that claims data reflect the full spectrum of patient exposure and outcomes, we believe our results are generalizable to the US insured population. Finally, our economic analysis did not include INR testing for patients taking warfarin. Eliminating the need for these tests would reduce the relative expenditure for the novel anticoagulants compared to warfarin, but only modestly.

Current European Society of Cardiology and Canadian Cardiovascular Society guidelines ${ }^{19}$ recommend use of one of the three novel agents over warfarin for the prevention of stroke or systemic embolism in patients with atrial fibrillation. In contrast, the American College of Cardiology/American Heart Association/Heart Rhythm Society guidelines offer no such preference. ${ }^{25}$ Our results demonstrate rapid adoption of novel anticoagulants, particularly among lower risk patients with atrial fibrillation, and correspondingly high health care cost burden. These findings point to the need to conduct ongoing surveillance of the adoption of new agents into clinical practice, as well as the need for robust, real-world comparative-effectiveness analyses of these medications, to enable patients and providers to make informed decisions about their relative benefit, safety, and cost-effectiveness. 


\section{REFERENCES}

1. Risk factors for stroke and efficacy of antithrombotic therapy in atrial fibrillation. Analysis of pooled data from five randomized controlled trials. Archives of internal medicine. Jul 11 1994;154(13):1449-1457.

2. Gomes T, Mamdani MM, Holbrook AM, Paterson JM, Juurlink DN. Persistence with therapy among patients treated with warfarin for atrial fibrillation. Arch Intern Med. Nov 26 2012;172(21):1687-1689.

3. Connolly SJ, Ezekowitz MD, Yusuf S, et al. Dabigatran versus warfarin in patients with atrial fibrillation. The New England journal of medicine. Sep 17 2009;361(12):1139-1151.

4. Patel MR, Mahaffey KW, Garg J, et al. Rivaroxaban versus warfarin in nonvalvular atrial fibrillation. The New England journal of medicine. Sep 8 2011;365(10):883-891.

5. Granger $\mathrm{CB}$, Alexander JH, McMurray JJ, et al. Apixaban versus warfarin in patients with atrial fibrillation. The New England journal of medicine. Sep 15 2011;365(11):981-992.

6. Kirley K, Qato DM, Kornfield R, Stafford RS, Alexander GC. National trends in oral anticoagulant use in the United States, 2007 to 2011. Circ Cardiovasc Qual Outcomes. Sep 1 2012;5(5):615621.

7. Steinberg BA, Holmes DN, Piccini JP, et al. Early Adoption of Dabigatran and Its Dosing in US Patients With Atrial Fibrillation: Results From the Outcomes Registry for Better Informed Treatment of Atrial Fibrillation. Journal of the American Heart Association. December 19, 2013 2013;2(6).

8. Gage BF, Waterman AD, Shannon W, Boechler M, Rich MW, Radford MJ. Validation of clinical classification schemes for predicting stroke: results from the National Registry of Atrial Fibrillation. JAMA. Jun 13 2001;285(22):2864-2870.

9. Lip GY, Nieuwlaat R, Pisters R, Lane DA, Crijns HJ. Refining clinical risk stratification for predicting stroke and thromboembolism in atrial fibrillation using a novel risk factor-based approach: the euro heart survey on atrial fibrillation. Chest. Feb 2010;137(2):263-272.

10. Pisters R, Lane DA, Nieuwlaat R, de Vos CB, Crijns HJ, Lip GY. A novel user-friendly score (HAS$B L E D)$ to assess 1-year risk of major bleeding in patients with atrial fibrillation: the Euro Heart Survey. Chest. Nov 2010;138(5):1093-1100.

11. Pradaxa (dabigatran etexilate mesylate): Drug Safety Communication - Safety Review of PostMarket Reports of Serious Bleeding Events. 2011; http://www.fda.gov/safety/medwatch/safetyinformation/safetyalertsforhumanmedicalproduct s/ucm282820.htm. Accessed December 23, 2013.

12. Artang R, Rome E, Nielsen JD, Vidaillet HJ. Meta-analysis of randomized controlled trials on risk of myocardial infarction from the use of oral direct thrombin inhibitors. Am J Cardiol. Dec 15 2013;112(12):1973-1979.

13. Mak KH. Coronary and mortality risk of novel oral antithrombotic agents: a meta-analysis of large randomised trials. BMJ Open. 2012;2(5).

14. Daiichi Sankyo Company. (2014 Jan 9). "Daiichi Sankyo Submits SAVAYSA(TM) (edoxaban) Tablets New Drug Application to the U.S. FDA for Once-Daily Use for Stroke Risk Reduction in Atrial Fibrillation and for the Treatment and Prevention of Recurrence of Venous Thromboembolism." Retrieved Jan 13, 2014, from http://www.daiichisankyo.com/media investors/media relations/press releases/detail/006065 .html.

15. Giugliano RP, Ruff CT, Braunwald E, et al. Edoxaban versus warfarin in patients with atrial fibrillation. N Engl J Med. Nov 28 2013;369(22):2093-2104.

16. Palladino M, Merli G, Thomson L. Evaluation of the oral direct factor Xa inhibitor - betrixaban. Expert Opin Investig Drugs. Nov 2013;22(11):1465-1472. 
17. Southworth, MR, Reichman ME, Unger EF. Dabigatran and postmarketing reports of bleeding. $N$ Engl J Med. 2013;368(14):1272-1274.

18. Avorn, J. The promise of pharmacoepidemiology in helping clinicians assess drug risk. Circulation. 2013;128(7):745-748.

19. Camm AJ, Lip GY, De Caterina R, et al. 2012 focused update of the ESC Guidelines for the management of atrial fibrillation: an update of the 2010 ESC Guidelines for the management of atrial fibrillation. Developed with the special contribution of the European Heart Rhythm Association. European heart journal. Nov 2012;33(21):2719-2747.

20. Canestaro WJ, Patrick AR, Avorn J, et al. Cost-effectiveness of oral anticoagulants for treatment of atrial fibrillation. Circ Cardiovasc Qual Outcomes. Nov 1 2013;6(6):724-731.

21. Limone BL, Baker WL, Kluger J, Coleman Cl. Novel anticoagulants for stroke prevention in atrial fibrillation: a systematic review of cost-effectiveness models. PLoS One. 2013;8(4):e62183.

22. Shah SV, Gage BF. Cost-effectiveness of dabigatran for stroke prophylaxis in atrial fibrillation. Circulation. Jun 7 2011;123(22):2562-2570.

23. Norberg J, Backstrom S, Jansson JH, Johansson L. Estimating the prevalence of atrial fibrillation in a general population using validated electronic health data. Clinical epidemiology. 2013;5:475-481.

24. Winkelmayer WC, Liu J, Patrick AR, Setoguchi S, Choudhry NK. Prevalence of atrial fibrillation and warfarin use in older patients receiving hemodialysis. Journal of nephrology. May-Jun 2012;25(3):341-353.

25. Wann LS, Curtis AB, Ellenbogen KA, et al. 2011 ACCF/AHA/HRS focused update on the management of patients with atrial fibrillation (update on Dabigatran): a report of the American College of Cardiology Foundation/American Heart Association Task Force on practice guidelines. Circulation. Mar 15 2011;123(10):1144-1150. 
Title: Patterns of Initiation of Oral Anticoagulants in Patients with Atrial Fibrillation

\section{Clinical Significance:}

- By mid-2013, novel anticoagulants accounted for $62 \%$ of new prescriptions and 98\% of anticoagulant-related medication costs

- Females, individuals in lower income areas and those with higher $\mathrm{CHADS}_{2}$ and HASBLED score have significantly lower odds of novel anticoagulant initiation

- Adoption patterns demonstrate divergence from the clinical trials on whose basis novel anticoagulants were approved; surveillance is needed to observe whether selection bias persists in patients initiating these medications 
Table 1: Baseline Demographic Characteristics, Clinical Characteristics, and Healthcare Utilization of the Study Cohort

\begin{tabular}{|c|c|c|c|c|c|c|}
\hline & All & Warfarin & Dabigatran & Rivaroxaban & Apixaban & p-val* \\
\hline \multicolumn{7}{|l|}{ Demographics } \\
\hline Members & 6893 & 4070 & 1982 & 821 & 20 & \\
\hline Gender (female) & $27.2 \%$ & $30.0 \%$ & $23.0 \%$ & $23.5 \%$ & $5.0 \%$ & $<.0001$ \\
\hline \multicolumn{7}{|l|}{ Age } \\
\hline Average age & 61.3 & 61.8 & 60.7 & 60.5 & 58.4 & $<.0001$ \\
\hline Age 18-54 & $22.3 \%$ & $21.5 \%$ & $23.6 \%$ & $23.4 \%$ & $20.0 \%$ & \\
\hline Age $55-64$ & $44.8 \%$ & $44.1 \%$ & $44.4 \%$ & $48.4 \%$ & $60.0 \%$ & \\
\hline Age 65-74 & $23.1 \%$ & $22.8 \%$ & $24.8 \%$ & $20.6 \%$ & $15.0 \%$ & \\
\hline Age $75+$ & $9.8 \%$ & $11.6 \%$ & $7.2 \%$ & $7.7 \%$ & $5.0 \%$ & \\
\hline \multicolumn{7}{|l|}{ Region } \\
\hline Northeast & $32.7 \%$ & $33.8 \%$ & $31.9 \%$ & $29.4 \%$ & $40.0 \%$ & 0.04 \\
\hline South & $38.2 \%$ & $36.0 \%$ & $41.0 \%$ & $42.1 \%$ & $35.0 \%$ & $<.0001$ \\
\hline Midwest & $8.3 \%$ & $8.2 \%$ & $9.1 \%$ & $7.2 \%$ & $10.0 \%$ & 0.24 \\
\hline West & $19.9 \%$ & $21.2 \%$ & $17.4 \%$ & $20.1 \%$ & $10.0 \%$ & 0.002 \\
\hline Comorbidity & & & Mean (SD) & & & \\
\hline $\mathrm{CHADS}_{2}$ score & $1.67(1.10)$ & $1.79(1.18)$ & $1.50(0.94)$ & $1.53(0.97)$ & $1.40(0.68)$ & $<.0001$ \\
\hline $\mathrm{CHA}_{2} \mathrm{DS}_{2}$-VASC score & $2.57(1.62)$ & $2.83(1.71)$ & $2.19(1.37)$ & $2.23(1.43)$ & $2.05(0.94)$ & $<.0001$ \\
\hline \multirow[t]{2}{*}{ HAS- BLED } & $1.96(1.16)$ & $2.08(1.22)$ & $1.77(1.01)$ & $1.81(1.08)$ & $1.60(0.82)$ & $<.0001$ \\
\hline & & & $\%$ & & & \\
\hline Coronary artery disease & $31 \%$ & $33 \%$ & $28 \%$ & $30 \%$ & $30 \%$ & $<.0001$ \\
\hline Congestive heart failure & $17 \%$ & $20 \%$ & $12 \%$ & $12 \%$ & $5 \%$ & $<.0001$ \\
\hline Hypertension & $91 \%$ & $91 \%$ & $91 \%$ & $92 \%$ & $95 \%$ & 0.68 \\
\hline Diabetes mellitus & $24 \%$ & $26 \%$ & $21 \%$ & $20 \%$ & $25 \%$ & $<.0001$ \\
\hline $\begin{array}{l}\text { Deep vein thrombosis or } \\
\text { pulmonary embolism }\end{array}$ & $10 \%$ & $15 \%$ & $2 \%$ & $3 \%$ & $5 \%$ & $<.0001$ \\
\hline Liver disease & $5 \%$ & $6 \%$ & $4 \%$ & $3 \%$ & $5 \%$ & 0.001 \\
\hline Renal dysfunction & $12 \%$ & $16 \%$ & $7 \%$ & $8 \%$ & $5 \%$ & $<.0001$ \\
\hline $\begin{array}{l}\text { Previous ischemic stroke } \\
\text { or transient ischemic } \\
\text { attack }\end{array}$ & $9 \%$ & $10 \%$ & $6 \%$ & $8 \%$ & $5 \%$ & $<.0001$ \\
\hline Hemorrhagic stroke & $1 \%$ & $1 \%$ & $0 \%$ & $0.1 \%$ & $0 \%$ & 0.003 \\
\hline Gastrointestinal bleeding & $4 \%$ & $4 \%$ & $3 \%$ & $3 \%$ & $0 \%$ & 0.001 \\
\hline Urogenital bleeding & $12 \%$ & $15 \%$ & $6 \%$ & $9 \%$ & $10 \%$ & $<.0001$ \\
\hline Other major bleeding & $4 \%$ & $5 \%$ & $2 \%$ & $2 \%$ & $0 \%$ & $<.0001$ \\
\hline $\begin{array}{l}\text { Bleeding history or } \\
\text { predisposition }\end{array}$ & $18 \%$ & $22 \%$ & $12 \%$ & $14 \%$ & $10 \%$ & $<.0001$ \\
\hline Healthcare Utilization & & & Mean (SD) & & & \\
\hline Number of medications & $8.25(4.92)$ & $8.63(5.15)$ & $7.56(4.48)$ & $8.05(4.61)$ & $7.15(3.60)$ & $<.0001$ \\
\hline Hospitalizations & $0.51(0.72)$ & $0.59(0.80)$ & $0.40(0.58)$ & $0.40(0.57)$ & $0.20(0.41)$ & $<.0001$ \\
\hline Hospital days & $4.52(13.64)$ & $6.28(16.86)$ & $2.07(6.36)$ & $1.82(4.18)$ & $0.65(1.42)$ & $<.0001$ \\
\hline Office visits & $9.59(9.99)$ & $10.25(11.18)$ & $8.71(7.81)$ & $8.45(8.04)$ & $8.75(8.75)$ & $<.0001$ \\
\hline Cardiologist visits & $2.07(2.65)$ & $1.92(2.77)$ & $2.35(2.54)$ & $2.14(2.21)$ & $2.40(2.72)$ & $<.0001$ \\
\hline \multirow[t]{2}{*}{ Neurologist visits } & $0.11(0.53)$ & $0.12(0.57)$ & $0.08(0.46)$ & $0.11(0.53)$ & $0.00(0.00)$ & 0.08 \\
\hline & & & $\%$ & & & \\
\hline $\begin{array}{l}\text { Hospitalization in } 30 \text { days } \\
\text { prior to treatment } \\
\text { initiation }\end{array}$ & $30 \%$ & $34 \%$ & $26 \%$ & $25 \%$ & $15 \%$ & $<.0001$ \\
\hline
\end{tabular}

*p-value for warfarin v. dabigatran or rivaroxaban 


\section{Table 2: Multivariable Analysis Predicting Initiation with a Novel Anticoagulant versus WarfarinAmong Patients with Atrial Fibrillation}

\begin{tabular}{|c|c|c|c|}
\hline \multirow{2}{*}{ Predictor } & \multicolumn{3}{|c|}{$\begin{array}{c}\text { Odds Ratio (95\% CI) of Initiating Therapy With a Novel } \\
\text { Anticoagulant vs. Warfarin }\end{array}$} \\
\hline & Model 1* & Model 2\# & Model $3^{\dagger}$ \\
\hline \multicolumn{4}{|l|}{ Age (vs. under 50) } \\
\hline $50-65$ & $0.98(0.82,1.16)$ & - & - \\
\hline $65+$ & $0.92(0.76,1.12)$ & - & - \\
\hline Calendar month from October 2010 & $1.06(1.05,1.06)$ & $1.06(1.05,1.06)$ & $1.06(1.05,1.06)$ \\
\hline Gender (Female) & $0.76(0.67,0.86)$ & $0.76(0.67,0.86)$ & $0.76(0.67,0.86)$ \\
\hline \multicolumn{4}{|l|}{ Region (vs. Northeast) } \\
\hline Midwest & $1.18(0.96,1.44)$ & $1.17(0.95,1.43)$ & $1.15(0.94,1.41)$ \\
\hline South & $1.36(1.20,1.55)$ & $1.37(1.21,1.56)$ & $1.37(1.21,1.56)$ \\
\hline West & $0.87(0.74,1.01)$ & $0.85(0.73,0.99)$ & $0.86(0.74,1.00)$ \\
\hline \multicolumn{4}{|l|}{ Median household income in zip code (vs. $<\$ 50,000$ ) } \\
\hline$\$ 50,000-\$ 99,999$ & $1.20(1.05,1.38)$ & $1.21(1.06,1.38)$ & $1.21(1.06,1.38)$ \\
\hline$\$ 100,000-\$ 149,999$ & $1.69(1.21,2.36)$ & $1.69(1.22,2.35)$ & $1.74(1.25,2.43)$ \\
\hline$\$ 150,000-\$ 200,000$ & $1.90(0.62,5.79)$ & $1.98(0.65,6.07)$ & $2.03(0.66,6.23)$ \\
\hline Percent black in zip code & $1.06(0.75,1.50)$ & $0.98(0.70,1.38)$ & $0.98(0.70,1.37)$ \\
\hline Percent graduated college or high school in zip code & $1.01(1.01,1.02)$ & $1.01(1.01,1.02)$ & $1.02(1.01,1.02)$ \\
\hline \multicolumn{4}{|l|}{ Comorbidity } \\
\hline Coronary artery disease & $1.00(0.88,1.14)$ & $0.92(0.81,1.04)$ & $0.92(0.81,1.04)$ \\
\hline Deep vein thrombosis or pulmonary embolism & $0.17(0.13,0.23)$ & $0.15(0.11,0.19)$ & $0.16(0.12,0.20)$ \\
\hline Congestive heart failure & $0.72(0.61,0.84)$ & - & - \\
\hline Previous myocardial infarction & $0.82(0.60,1.11)$ & - & - \\
\hline Diabetes mellitus & $0.86(0.75,0.98)$ & - & - \\
\hline Alcohol use & $1.12(0.80,1.57)$ & - & - \\
\hline NSAID, aspirin, clopidogrel, prasugrel, or ticagrelor use & $1.00(0.88,1.15)$ & - & - \\
\hline Stroke & $0.71(0.60,0.84)$ & - & - \\
\hline Bleeding history or predisposition & $0.64(0.55,0.75)$ & - & - \\
\hline Abnormal liver function & $0.92(0.70,1.20)$ & - & - \\
\hline Hypertension & $1.20(0.99,1.45)$ & - & - \\
\hline Renal dysfunction & $0.64(0.52,0.77)$ & - & - \\
\hline $\mathrm{CHADS}_{2}$ score (per 1-point increase) & - & $0.80(0.76,0.84)$ & - \\
\hline HAS-BLED score (per 1-point increase) & - & - & $0.82(0.78,0.87)$ \\
\hline
\end{tabular}

*Model 1 includes age, gender, race, income, geographic region, calendar time, and investigator selected clinical diagnoses.

\#Model 2 includes age, gender, race, income, geographic region, calendar time, and CHADS 2 score.

†Model 3 includes age, gender, race, income, geographic region, calendar time and HAS-BLED score. 
Table 1: Baseline Demographic Characteristics, Clinical Characteristics, and Healthcare Utilization of the Study Cohort

\begin{tabular}{|c|c|c|c|c|c|c|}
\hline & All & Warfarin & Dabigatran & Rivaroxaban & Apixaban & p-val* \\
\hline \multicolumn{7}{|l|}{ Demographics } \\
\hline Members & 6893 & 4070 & 1982 & 821 & 20 & \\
\hline Gender (female) & $27.2 \%$ & $30.0 \%$ & $23.0 \%$ & $23.5 \%$ & $5.0 \%$ & $<.0001$ \\
\hline \multicolumn{7}{|l|}{ Age } \\
\hline Average age & 61.3 & 61.8 & 60.7 & 60.5 & 58.4 & $<.0001$ \\
\hline Age 18-54 & $22.3 \%$ & $21.5 \%$ & $23.6 \%$ & $23.4 \%$ & $20.0 \%$ & \\
\hline Age $55-64$ & $44.8 \%$ & $44.1 \%$ & $44.4 \%$ & $48.4 \%$ & $60.0 \%$ & \\
\hline Age 65-74 & $23.1 \%$ & $22.8 \%$ & $24.8 \%$ & $20.6 \%$ & $15.0 \%$ & \\
\hline Age $75+$ & $9.8 \%$ & $11.6 \%$ & $7.2 \%$ & $7.7 \%$ & $5.0 \%$ & \\
\hline \multicolumn{7}{|l|}{ Region } \\
\hline Northeast & $32.7 \%$ & $33.8 \%$ & $31.9 \%$ & $29.4 \%$ & $40.0 \%$ & 0.04 \\
\hline South & $38.2 \%$ & $36.0 \%$ & $41.0 \%$ & $42.1 \%$ & $35.0 \%$ & $<.0001$ \\
\hline Midwest & $8.3 \%$ & $8.2 \%$ & $9.1 \%$ & $7.2 \%$ & $10.0 \%$ & 0.24 \\
\hline West & $19.9 \%$ & $21.2 \%$ & $17.4 \%$ & $20.1 \%$ & $10.0 \%$ & 0.002 \\
\hline Comorbidity & & & Mean (SD) & & & \\
\hline $\mathrm{CHADS}_{2}$ score & $1.67(1.10)$ & $1.79(1.18)$ & $1.50(0.94)$ & $1.53(0.97)$ & $1.40(0.68)$ & $<.0001$ \\
\hline $\mathrm{CHA}_{2} \mathrm{DS}_{2}$-VASC score & $2.57(1.62)$ & $2.83(1.71)$ & $2.19(1.37)$ & $2.23(1.43)$ & $2.05(0.94)$ & $<.0001$ \\
\hline \multirow[t]{2}{*}{ HAS- BLED } & $1.96(1.16)$ & $2.08(1.22)$ & $1.77(1.01)$ & $1.81(1.08)$ & $1.60(0.82)$ & $<.0001$ \\
\hline & & & $\%$ & & & \\
\hline Coronary artery disease & $31 \%$ & $33 \%$ & $28 \%$ & $30 \%$ & $30 \%$ & $<.0001$ \\
\hline Congestive heart failure & $17 \%$ & $20 \%$ & $12 \%$ & $12 \%$ & $5 \%$ & $<.0001$ \\
\hline Hypertension & $91 \%$ & $91 \%$ & $91 \%$ & $92 \%$ & $95 \%$ & 0.68 \\
\hline Diabetes mellitus & $24 \%$ & $26 \%$ & $21 \%$ & $20 \%$ & $25 \%$ & $<.0001$ \\
\hline $\begin{array}{l}\text { Deep vein thrombosis or } \\
\text { pulmonary embolism }\end{array}$ & $10 \%$ & $15 \%$ & $2 \%$ & $3 \%$ & $5 \%$ & $<.0001$ \\
\hline Liver disease & $5 \%$ & $6 \%$ & $4 \%$ & $3 \%$ & $5 \%$ & 0.001 \\
\hline Renal dysfunction & $12 \%$ & $16 \%$ & $7 \%$ & $8 \%$ & $5 \%$ & $<.0001$ \\
\hline $\begin{array}{l}\text { Previous ischemic stroke } \\
\text { or transient ischemic } \\
\text { attack }\end{array}$ & $9 \%$ & $10 \%$ & $6 \%$ & $8 \%$ & $5 \%$ & $<.0001$ \\
\hline Hemorrhagic stroke & $1 \%$ & $1 \%$ & $0 \%$ & $0.1 \%$ & $0 \%$ & 0.003 \\
\hline Gastrointestinal bleeding & $4 \%$ & $4 \%$ & $3 \%$ & $3 \%$ & $0 \%$ & 0.001 \\
\hline Urogenital bleeding & $12 \%$ & $15 \%$ & $6 \%$ & $9 \%$ & $10 \%$ & $<.0001$ \\
\hline Other major bleeding & $4 \%$ & $5 \%$ & $2 \%$ & $2 \%$ & $0 \%$ & $<.0001$ \\
\hline $\begin{array}{l}\text { Bleeding history or } \\
\text { predisposition }\end{array}$ & $18 \%$ & $22 \%$ & $12 \%$ & $14 \%$ & $10 \%$ & $<.0001$ \\
\hline Healthcare Utilization & & & Mean (SD) & & & \\
\hline Number of medications & $8.25(4.92)$ & $8.63(5.15)$ & $7.56(4.48)$ & $8.05(4.61)$ & $7.15(3.60)$ & $<.0001$ \\
\hline Hospitalizations & $0.51(0.72)$ & $0.59(0.80)$ & $0.40(0.58)$ & $0.40(0.57)$ & $0.20(0.41)$ & $<.0001$ \\
\hline Hospital days & $4.52(13.64)$ & $6.28(16.86)$ & $2.07(6.36)$ & $1.82(4.18)$ & $0.65(1.42)$ & $<.0001$ \\
\hline Office visits & $9.59(9.99)$ & $10.25(11.18)$ & $8.71(7.81)$ & $8.45(8.04)$ & $8.75(8.75)$ & $<.0001$ \\
\hline Cardiologist visits & $2.07(2.65)$ & $1.92(2.77)$ & $2.35(2.54)$ & $2.14(2.21)$ & $2.40(2.72)$ & $<.0001$ \\
\hline \multirow[t]{2}{*}{ Neurologist visits } & $0.11(0.53)$ & $0.12(0.57)$ & $0.08(0.46)$ & $0.11(0.53)$ & $0.00(0.00)$ & 0.08 \\
\hline & & & $\%$ & & & \\
\hline $\begin{array}{l}\text { Hospitalization in } 30 \text { days } \\
\text { prior to treatment } \\
\text { initiation }\end{array}$ & $30 \%$ & $34 \%$ & $26 \%$ & $25 \%$ & $15 \%$ & $<.0001$ \\
\hline
\end{tabular}

*p-value for warfarin v. dabigatran or rivaroxaban 


\section{Table 2: Multivariable Analysis Predicting Initiation with a Novel Anticoagulant versus WarfarinAmong Patients with Atrial Fibrillation}

\begin{tabular}{|c|c|c|c|}
\hline \multirow{2}{*}{ Predictor } & \multicolumn{3}{|c|}{$\begin{array}{c}\text { Odds Ratio (95\% CI) of Initiating Therapy With a Novel } \\
\text { Anticoagulant vs. Warfarin }\end{array}$} \\
\hline & Model 1* & Model 2\# & Model $3^{\dagger}$ \\
\hline \multicolumn{4}{|l|}{ Age (vs. under 50) } \\
\hline $50-65$ & $0.98(0.82,1.16)$ & - & - \\
\hline $65+$ & $0.92(0.76,1.12)$ & - & - \\
\hline Calendar month from October 2010 & $1.06(1.05,1.06)$ & $1.06(1.05,1.06)$ & $1.06(1.05,1.06)$ \\
\hline Gender (Female) & $0.76(0.67,0.86)$ & $0.76(0.67,0.86)$ & $0.76(0.67,0.86)$ \\
\hline \multicolumn{4}{|l|}{ Region (vs. Northeast) } \\
\hline Midwest & $1.18(0.96,1.44)$ & $1.17(0.95,1.43)$ & $1.15(0.94,1.41)$ \\
\hline South & $1.36(1.20,1.55)$ & $1.37(1.21,1.56)$ & $1.37(1.21,1.56)$ \\
\hline West & $0.87(0.74,1.01)$ & $0.85(0.73,0.99)$ & $0.86(0.74,1.00)$ \\
\hline \multicolumn{4}{|l|}{ Median household income in zip code (vs. $<\$ 50,000$ ) } \\
\hline$\$ 50,000-\$ 99,999$ & $1.20(1.05,1.38)$ & $1.21(1.06,1.38)$ & $1.21(1.06,1.38)$ \\
\hline$\$ 100,000-\$ 149,999$ & $1.69(1.21,2.36)$ & $1.69(1.22,2.35)$ & $1.74(1.25,2.43)$ \\
\hline$\$ 150,000-\$ 200,000$ & $1.90(0.62,5.79)$ & $1.98(0.65,6.07)$ & $2.03(0.66,6.23)$ \\
\hline Percent black in zip code & $1.06(0.75,1.50)$ & $0.98(0.70,1.38)$ & $0.98(0.70,1.37)$ \\
\hline Percent graduated college or high school in zip code & $1.01(1.01,1.02)$ & $1.01(1.01,1.02)$ & $1.02(1.01,1.02)$ \\
\hline \multicolumn{4}{|l|}{ Comorbidity } \\
\hline Coronary artery disease & $1.00(0.88,1.14)$ & $0.92(0.81,1.04)$ & $0.92(0.81,1.04)$ \\
\hline Deep vein thrombosis or pulmonary embolism & $0.17(0.13,0.23)$ & $0.15(0.11,0.19)$ & $0.16(0.12,0.20)$ \\
\hline Congestive heart failure & $0.72(0.61,0.84)$ & - & - \\
\hline Previous myocardial infarction & $0.82(0.60,1.11)$ & - & - \\
\hline Diabetes mellitus & $0.86(0.75,0.98)$ & - & - \\
\hline Alcohol use & $1.12(0.80,1.57)$ & - & - \\
\hline NSAID, aspirin, clopidogrel, prasugrel, or ticagrelor use & $1.00(0.88,1.15)$ & - & - \\
\hline Stroke & $0.71(0.60,0.84)$ & - & - \\
\hline Bleeding history or predisposition & $0.64(0.55,0.75)$ & - & - \\
\hline Abnormal liver function & $0.92(0.70,1.20)$ & - & - \\
\hline Hypertension & $1.20(0.99,1.45)$ & - & - \\
\hline Renal dysfunction & $0.64(0.52,0.77)$ & - & - \\
\hline $\mathrm{CHADS}_{2}$ score (per 1-point increase) & - & $0.80(0.76,0.84)$ & - \\
\hline HAS-BLED score (per 1-point increase) & - & - & $0.82(0.78,0.87)$ \\
\hline
\end{tabular}

*Model 1 includes age, gender, race, income, geographic region, calendar time, and investigator selected clinical diagnoses.

\#Model 2 includes age, gender, race, income, geographic region, calendar time, and CHADS 2 score.

†Model 3 includes age, gender, race, income, geographic region, calendar time and HAS-BLED score. 
Figure 1: Monthly Trends in Oral Anticoagulant Initiation (Panel A) and Total Spending (Panel B)

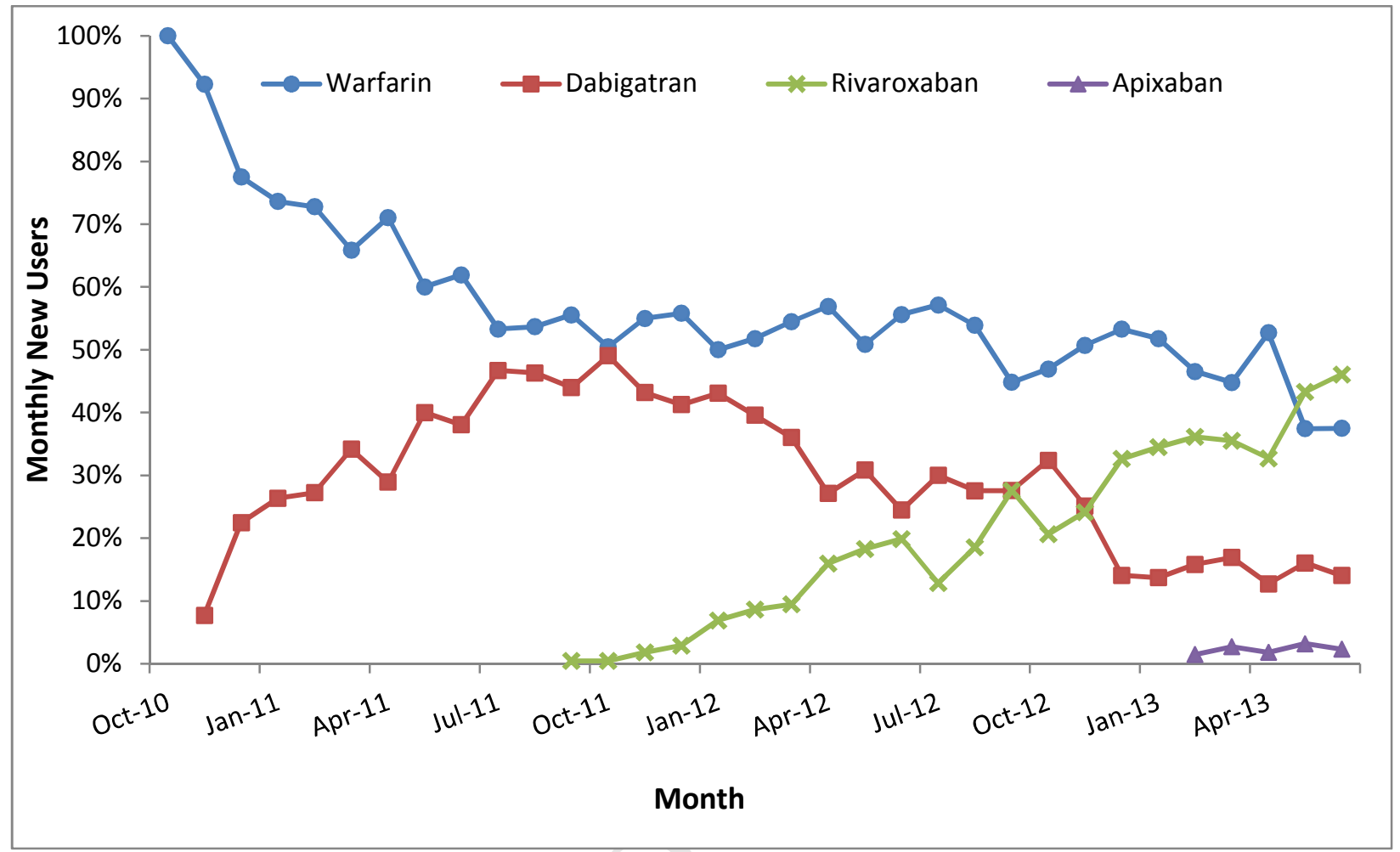




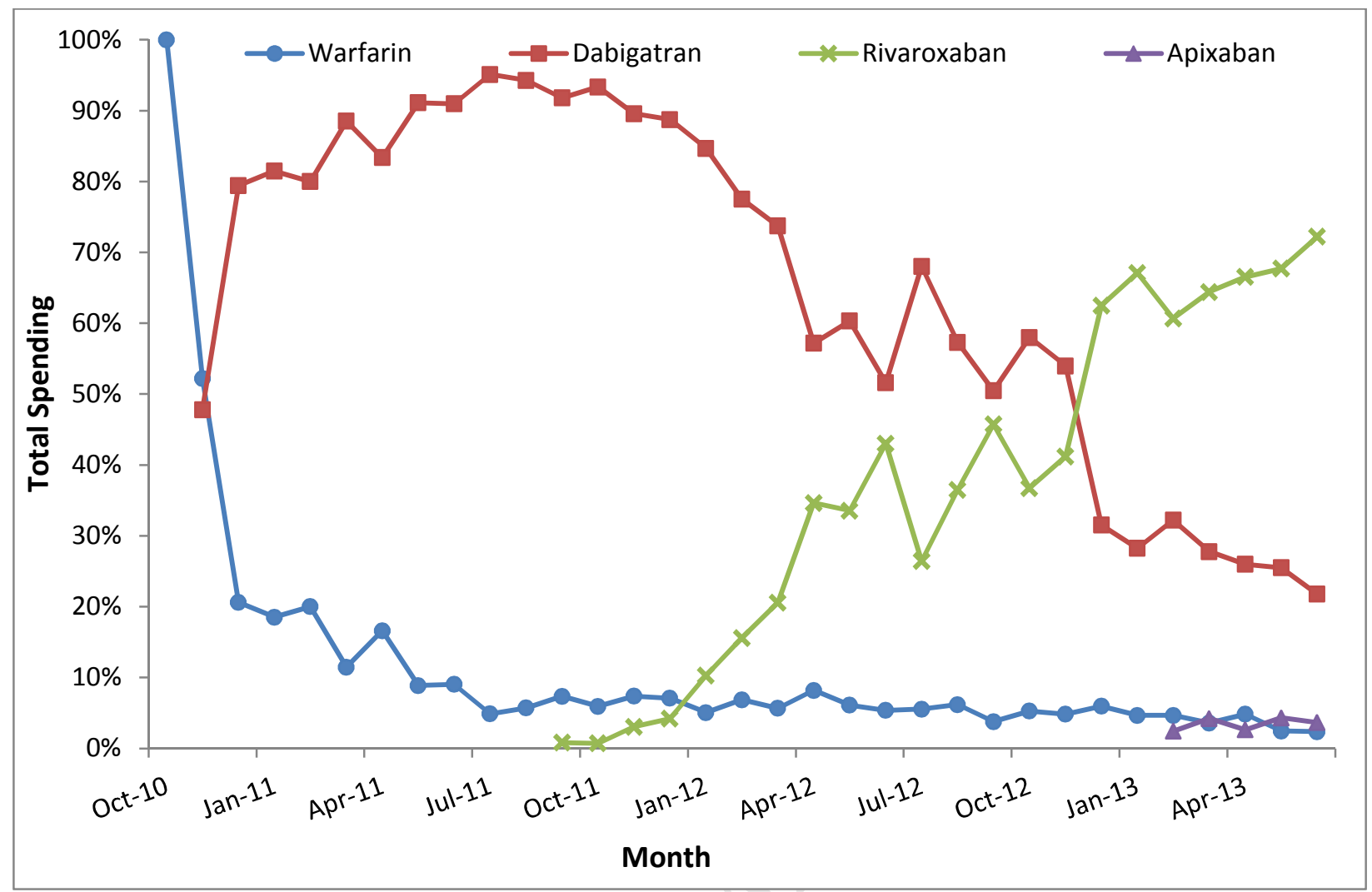


Figure 2: Number of Warfarin and Novel Anticoagulant Initiators by CHADS $_{2}$ Score during Study Period*

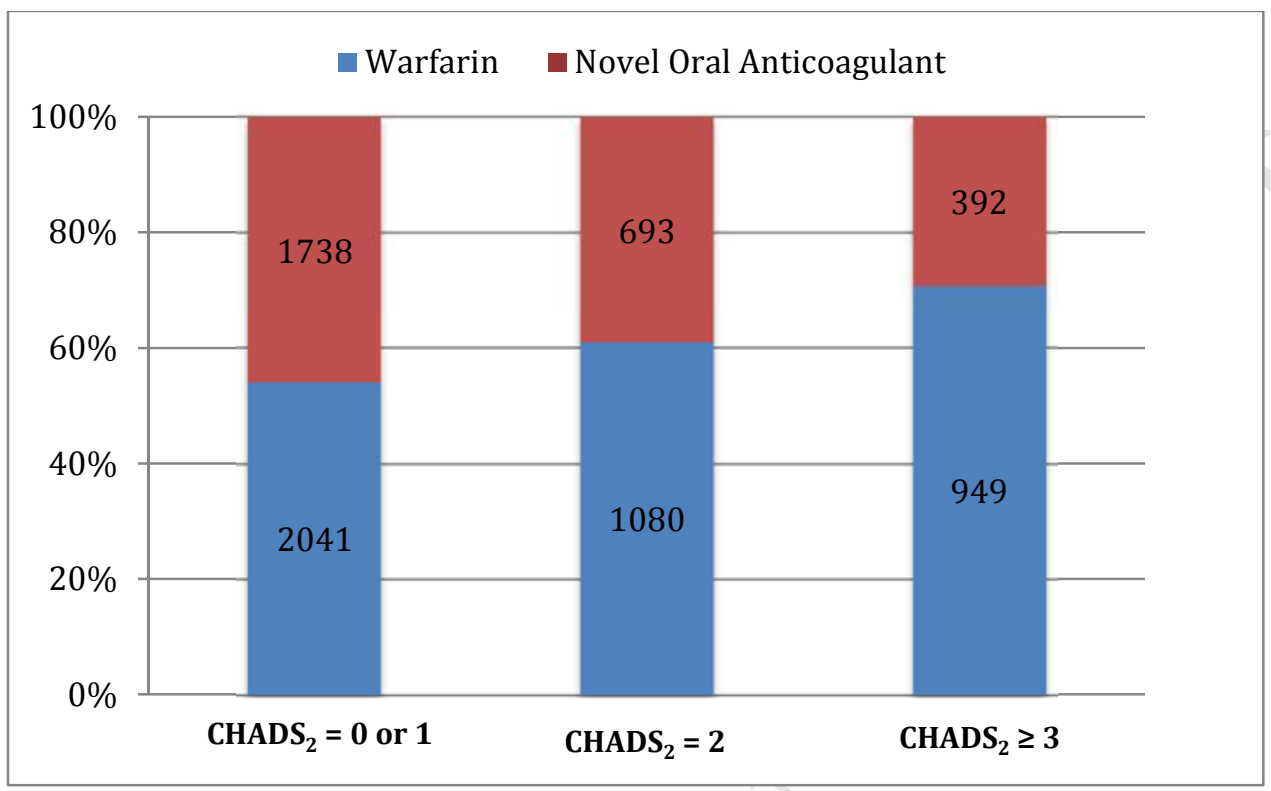

${ }^{*} \mathbf{p}<0.0001$ test for trend 
Figure 2: Number of Warfarin and Novel Anticoagulant Initiators by CHADS $_{2}$ Score during Study Period*

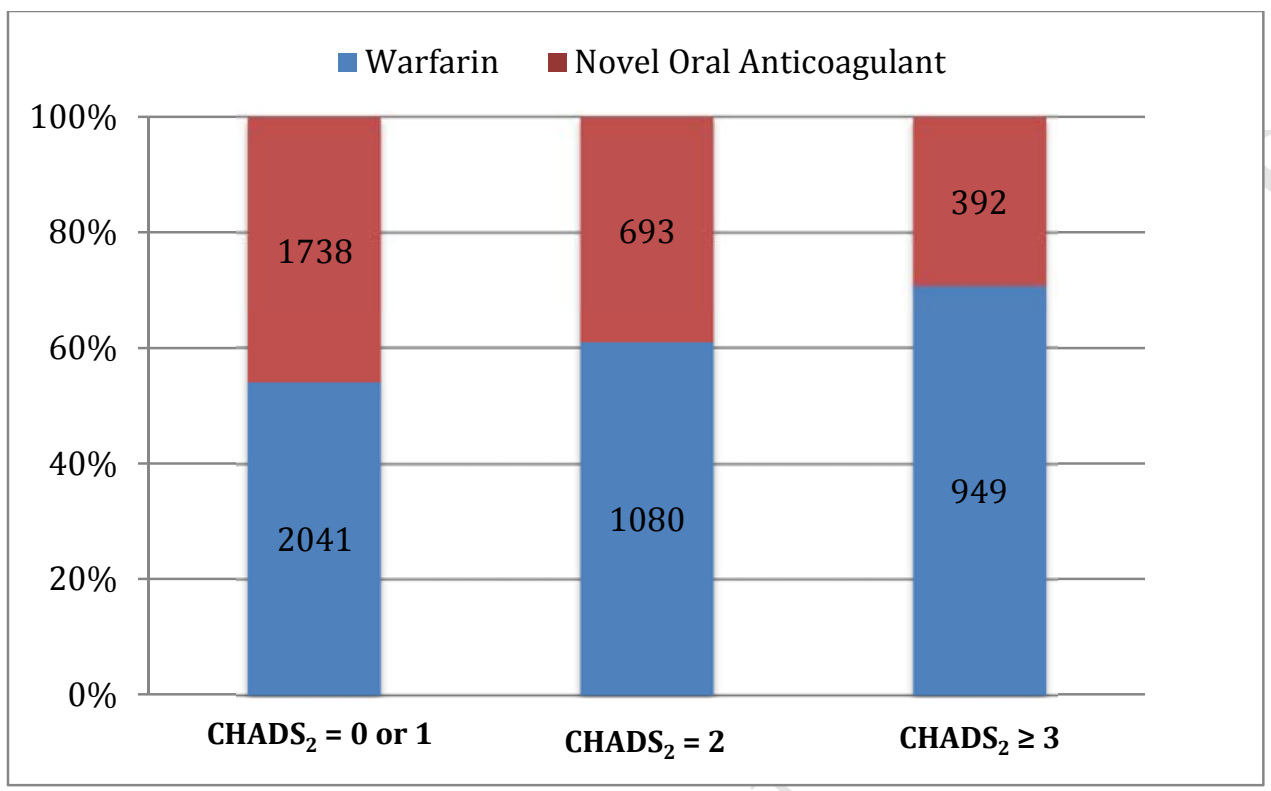

${ }^{*} \mathbf{p}<0.0001$ test for trend 
Figure 3: Accumulated Insurer Amount (Panel A) and Patient Out-of-Pocket Amount (Panel B) by Anticoagulant
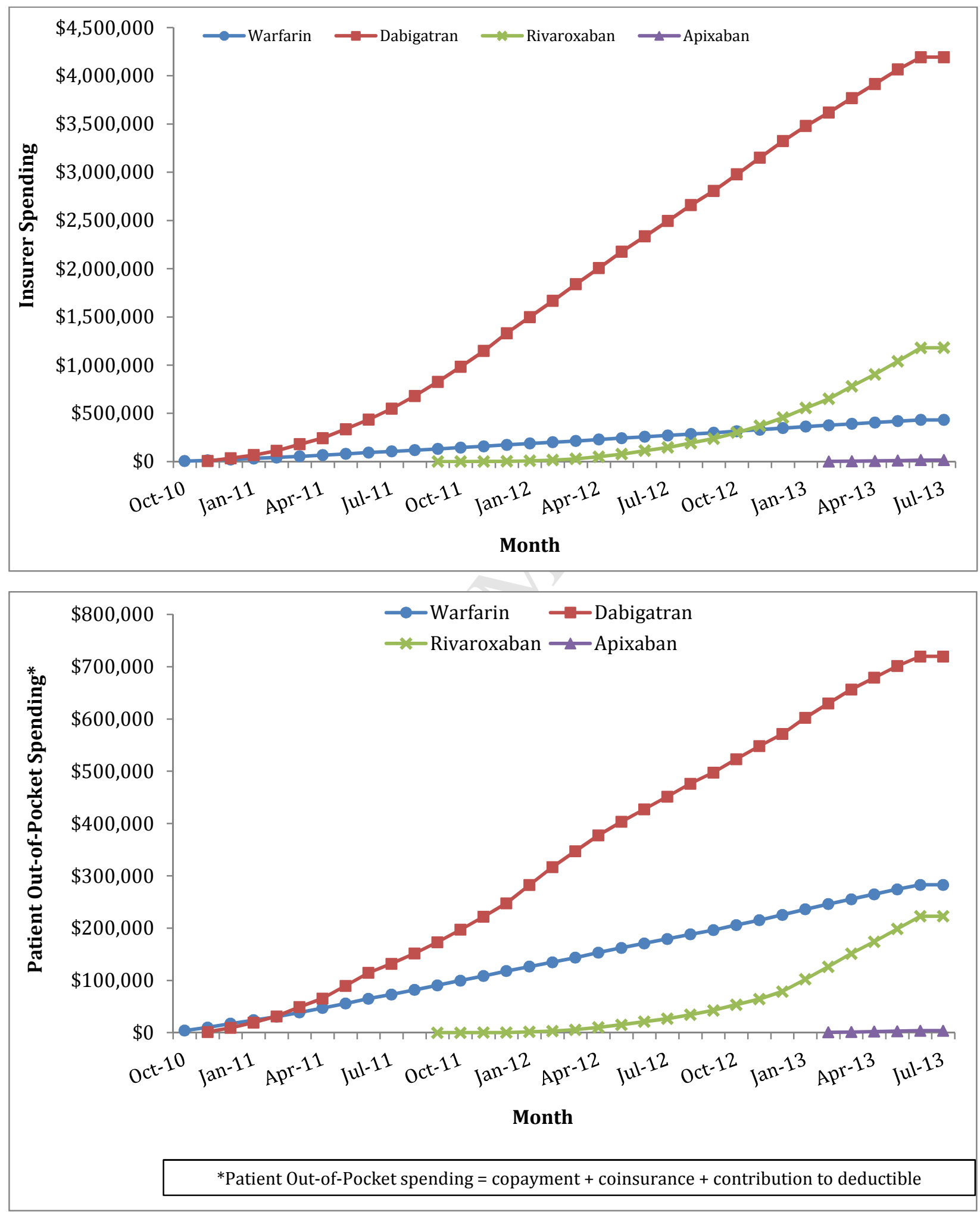
Figure 4: Total patient and insurer spending during 6 months after initiation stratified by anticoagulant on which patients were started

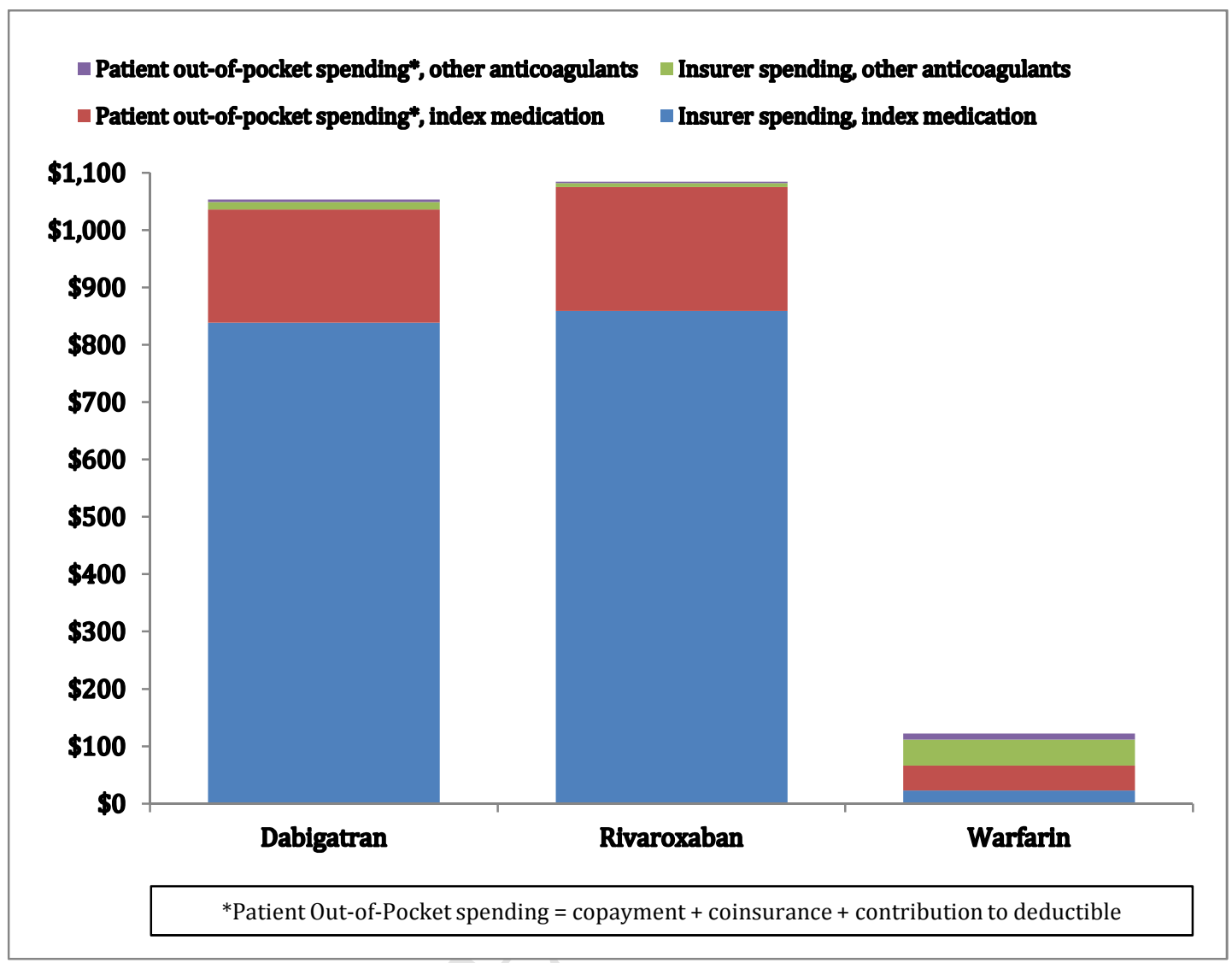




\section{Appendix A: Study Cohort Construction}

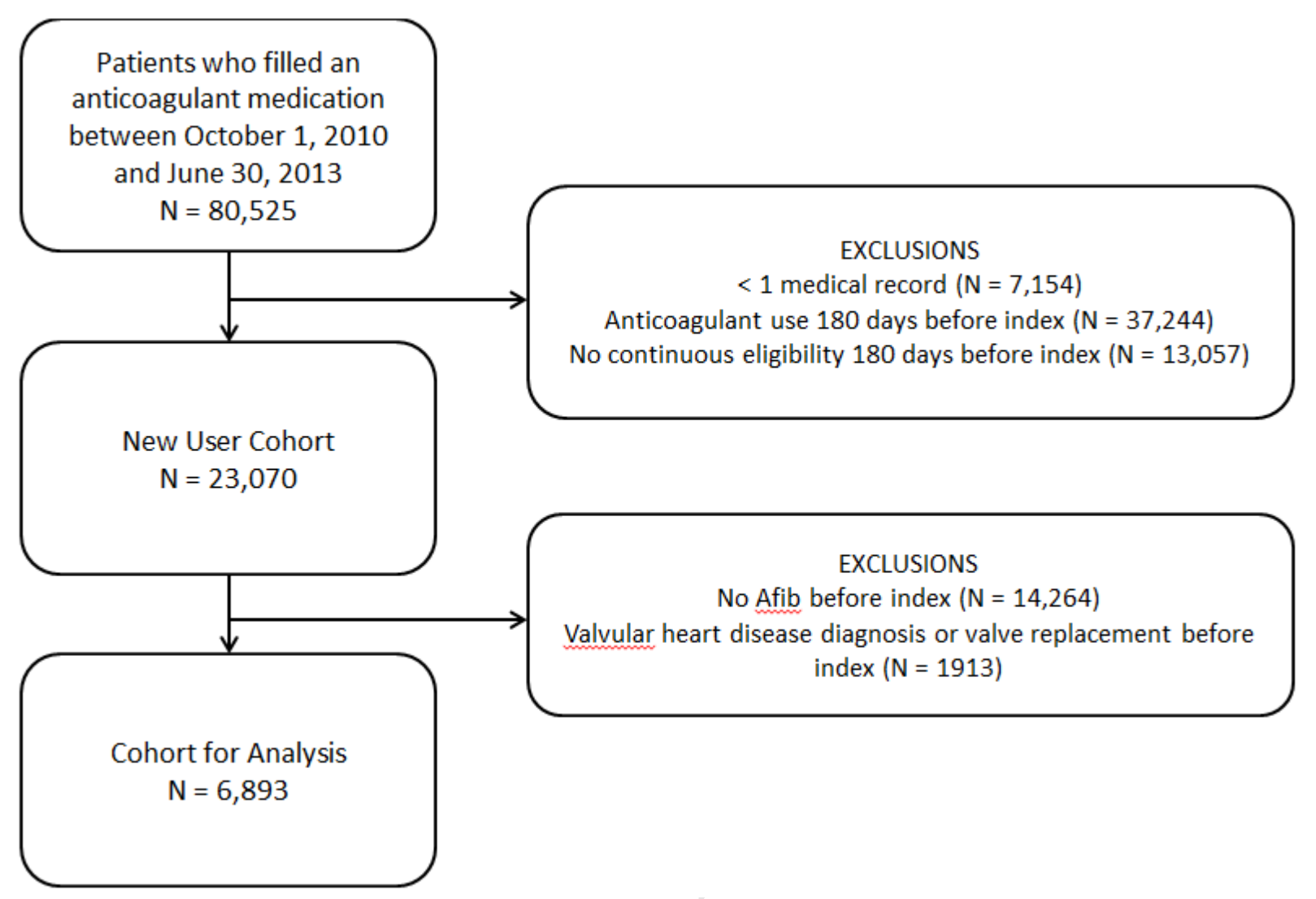

